\title{
EFEITO DE SUBSTRATOS NA ACLIMATIZAÇÃO DE MUDAS MICROPROPAGADAS DE ABACAXIZEIRO CV. PÉROLA
}

\author{
Acclimatization of micropropagated pineapple plants cv. "Pérola": substrata effect
}

\author{
Maria Aparecida Moreira', Janice Guedes de Carvalho ${ }^{2}$, Moacir Pasqual', \\ Chrystiane Borges Fráguas ${ }^{4}$, Adriano Bortolotti da Silva ${ }^{5}$
}

\begin{abstract}
RESUMO
Objetivou-se com este trabalho verificar o efeito da matéria orgânica como componente de substratos para mudas micropropagadas de abacaxizeiro cv. Pérola em fase de aclimatização. Mudas micropropagadas de abacaxizeiro cv. Pérola, selecionadas de acordo com o peso (aproximadamente $2 \mathrm{~g}$ ), foram plantadas em bandejas de isopor de 72 células de $120 \mathrm{~cm}^{3}$ contendo proporções de substratos com terra, esterco bovino, Plantmax e matéria orgânica. O delineamento estatístico utilizado foi o inteiramente casualizado com 4 repetições e 3 plantas por parcela. As avaliações foram feitas 90 dias após o plantio, quando se avaliou: altura da planta, comprimento de raiz, peso de matéria fresca de raiz e parte aérea, peso de matéria seca de raiz e parte aérea e número de folhas. Com os resultados obtidos, conclui-se que a matéria orgânica tem efeito significativo no desenvolvimento das mudas. Com o substrato contendo terra, esterco e Plantmax foi obtido o melhor desenvolvimento das raízes e parte aérea.
\end{abstract}

Termos para indexação: Cultura de tecidos, Ananas comosus, matéria orgânica.

\begin{abstract}
The objective of this work was to evaluate the effect of the organic matter as component of substrata for micropropagated plants of pineapple cv. Pérola in the acclimatization phase. Micropropagated plants were selected according to the weight (approximately $2 \mathrm{~g}$ ) and planted in trays with 72 cels of $120 \mathrm{~cm}^{3}$, containing substrata made of soil, bovine manure, Plantmax and organic matter at different proportions. At 90 days after planting, the following parameters were evaluated: height of the plant, root length, weight of fresh matter of root and aerial part, dry matter weight of root and aerial part and number of leaves. The obtained results allowed to conclude that the organic matter has significant effect on the development of the seedlings. The best results for the development of the roots and aerial part were obtained with substratum containing soil, manure and Plantmax.
\end{abstract}

Index terms: Tissue culture, Ananas comosus, organic matter.

(Recebido para publicação em 27 de abril de 2004 e aprovado em 22 de março de 2005)

\section{INTRODUÇÃO}

A técnica de aclimatização das plantas micropropagadas consiste em retirar a planta da condição 'in vitro' e transferi-la para casa-de-vegetação, com o objetivo de superar as dificuldades que as plantas enfrentam quando ocorre a mudança de ambiente. O sucesso dessa técnica requer que as plantas que se desenvolveram heterotroficamente sob condições de alta umidade, posteriormente se desenvolvam autotroficamente em condições de moderada ou baixa umidade (ZIMMERMAN, 1988). Diante desses fatores é necessário que as plantas micropropagadas passem por um período de aclimatização antes de serem transferidas para condições de campo.

Para muitas espécies a aclimatização é considerada uma fase crítica da micropropagação, sendo um dos maiores obstáculos à aplicação prática da cultura de tecidos na propagação de plantas, devido à grande diferença entre as duas condições ambientais (READ \& FELLMAN, 1985). A perda de vigor e a subseqüente morte devido ao dessecamento são dois sérios problemas que ocorrem com plantas transferidas das condições 'in vitro' para casa-devegetação (SUTTER \& HUTZELL, 1984).

Nos métodos que favorecem o crescimento das mudas após a aclimatização estão incluídas técnicas como: enraizamento 'ex vitro' ou 'in vivo' (BIASI, 1996; PASQUAL \& LOPES, 1991), escolha do substrato adequado (NORMAH et al., 1995), uso de micorrizas (CORSATO, 1993) e uso de inoculantes de bactérias fixadoras de nitrogênio, no caso de leguminosas.

A escolha de um substrato adequado reduz a mortalidade de plantas durante a aclimatização. Dentre os mais utilizados pode-se citar vermiculita, perlita, areia, turfa, casca de eucalipto ou Pinus curtida, casca de arroz carbonizada e pó de carvão, cujas proporções variam conforme a espécie (GRATTAPAGLIA \& MACHADO, 1990).

\footnotetext{
${ }^{1}$ Engenheira Agrônoma, Professor do Departamento de Agronomia/Fesurv - bianch@bol.com.br

2 Professora Titular, Departamento de Ciência do Solo, Universidade Federal de Lavras/UFLA - Cx. P. 3037 - $37200-000$ - Lavras, MG

3 Professor Titular Departamento de Agricultura, Universidade Federal de Lavras/UFLA - Cx. P. 3037 - 37200-000 - Lavras, MG - mpasqual@ufla.br

${ }^{4}$ Engenheira Agrônoma, Doutoranda - UNESP/Botucatu/SP

${ }^{5}$ Engenheiro Agrônomo, Doutorando - Departamento de Agricultura/DAG - Universidade Federal de Lavras/UFLA - Cx. P. 3037 - $37200-000$ Lavras, MG.
} 
De acordo com Hoffmann et al. (1996), um bom substrato deve ser firme e denso o suficiente para dar sustentação até o enraizamento; não encolher ou expandir com a variação da umidade; reter água em quantidade adequada; e ser suficientemente poroso para permitir a drenagem da água e a aeração. Deve também, estar livre de invasoras, nematóides ou outros patógenos; não apresentar níveis excessivos de salinidade e permitir a esterilização por vapor.

A utilização de materiais orgânicos deve considerar o fato de que estes podem causar excesso ou deficiência de nutrientes, devido a não quantificação precisa dos nutrientes existentes na matéria orgânica, além da necessidade de estar bem curtidos, não sendo aconselhável o uso de resíduos em fermentação ou com elevada relação C/N (HOFFMANN et al., 1996). O húmus ou a matéria orgânica não são apenas fonte de nutrientes, mas também têm propriedades de natureza coloidal, decorrentes de sua estrutura orgânica complexa, aliada a uma fina subdivisão de partículas (RAIJ, 1991).

Sousa (1994) constatou aumento em várias características de mudas de bananeira obtidas por cultura de meristemas, quando utilizou $45 \%$ de esterco de galinha em relação à sua ausência na composição de substratos. $\mathrm{O}$ esterco curtido de gado adicionado ao substrato proporcionou maior crescimento de mudas de mamoeiro (MULLER et al., 1979). Na formação de mudas de maracujazeiro, melhores resultados são obtidos ao acrescentarem-se 100, 200 e $300 \mathrm{~L}$ de esterco de curral por $\mathrm{m}^{3}$ de solo (PEIXOTO, 1986).

O esterco de galinha é mais rico em nutrientes em comparação ao de outros animais domésticos, pois contém menor umidade, dejeções sólidas e líquidas misturadas e geralmente é proveniente de aves criadas com rações concentradas (KIEHL, 1985). No entanto, os materiais são escolhidos em função de sua disponibilidade e propriedades físicas (SOUZA, 1983).

Em mudas micropropagadas de abacaxizeiro, as misturas de solo/xaxim/turfa e solo/xaxim/areia/húmus proporcionaram maior crescimento das plantas, sem afetar o índice de sobrevivência (FAUTH et al., 1994), que pode chegar próximo a $100 \%$ para plantas maiores que $3 \mathrm{~cm}$ (MOORE et al., 1992).

Visou-se com este trabalho foi verificar o efeito da matéria orgânica como componente de substratos para mudas micropropagadas de abacaxizeiro cv. Pérola em fase de aclimatização.

\section{MATERIAL E MÉTODOS}

Foram utilizadas mudas micropropagadas de abacaxizeiro 'Pérola' que se encontravam em meio MS sem reguladores de crescimento. As mudas foram selecionadas por peso (em torno de $2 \mathrm{~g}$ ), lavadas para retirar o excesso de meio de cultura e plantadas em bandejas de isopor, com 72 células de $120 \mathrm{~cm}^{3}$ contendo os substratos e mantidas em casa-de-vegetação com nebulização intermitente.

Os substratos utilizados foram solo de subsuperfície, esterco bovino, Plantmax e composto orgânico, conforme Tabela 1. O solo utilizado foi misturado com areia na proporção de 2:1 depois de ser peneirado, constituindo a mistura padrão para todas as misturas onde se utilizou solo.

$\mathrm{O}$ delineamento experimental utilizado foi o inteiramente casualizado com 11 tratamentos, 4 repetições e 3 plantas por parcela (12 plantas por tratamento), totalizando 132 plantas. As avaliações foram feitas 90 dias após o plantio das mudas, quantificando-se os seguintes parâmetros: altura da planta, comprimento de raiz, peso de matéria fresca de raiz e parte aérea, peso de matéria seca de raiz e parte aérea e número de folhas.

\section{RESULTADOS E DISCUSSÃO}

A aclimatização de mudas micropropagadas de abacaxizeiro resultou em altas taxas de sobrevivência (dados não mostrados), aproximadamente $95 \%$ para todos os tratamentos testados.

Foi observado que os substratos utilizados interferiram de forma diferenciada nas variáveis avaliadas (Tabela 2).

Para todas as variáveis analisadas o substrato que mostrou os piores resultados foi o substrato 1 (solo), ou seja, o substrato solo sem nenhum componente orgânico, evidenciando a necessidade de se ter mistura de substratos, principalmente um componente orgânico, para o bom desenvolvimento de mudas micropropagadas de abacaxizeiro durante a aclimatização.

As variáveis analisadas relativas à parte aérea foram favorecidas pelo uso da matéria orgânica. Os substratos 3 (plantmax), 1 e 6 (solo + plantmax ) mostraram piores desempenhos para massa fresca e seca da parte aérea. Para as variáveis altura de planta e número de folhas os melhores substratos foram 4 (composto orgânico), 5 (solo + esterco) e 8 (solo + esterco + plantmax), enquanto que, resultados pouco significativos foram obtidos com os substratos 1 para número de folhas e 3 e 1 para altura das plantas. O número de folhas é característica importante, e,

Ciênc. agrotec., Lavras, v. 30, n. 5, p. 875-879, set./out., 2006 
possivelmente, mudas com maior número de folhas têm maior índice de pegamento no campo, pois as folhas são as estruturas responsáveis pela captação de energia solar e produção de matéria orgânica através da fotossíntese.

Pode-se observar que para as variáveis analisadas na parte aérea, os melhores resultados foram obtidos com os substratos 4,5 e 8 , mostrando que as plantas com maior altura e número de folhas apresentaram também bom desempenho de massa fresca e seca da parte da parte aérea. Provavelmente, esses substratos $(4,5$ e 8$)$ tiveram a porosidade adequada para o desenvolvimento da parte aérea das plantas. Vários autores têm tentado obter uma porosidade ideal, possibilitando o fornecimento de água e oxigênio de maneira adequada, pelo ajuste da taxa de constituintes de substrato (POOLE \& WATERS, 1972; PAUL \& LEE, 1976). Para isto diversos materiais são utilizados: solo, areia, turfa, serragem, casca de arroz carbonizada, húmus, resíduos orgânicos, entre outros.

O húmus em mistura com substrato comercial agromix ${ }^{\circledR} \quad(1: 1)$ apresentou resposta semelhante para abacaxi (Ananas comosus L.) quando utilizado como substrato para plantas vindas de cultivo in vitro (SILVA et al., 1998). Salvador (2000) e Silva (2001) obtiveram ótimos resultados em cultivo convencional de gloxínia em estufa, utilizando-se como substrato composto de vermiculita, húmus e perlita $(1: 2: 0,5)$, apresentando média de 11 botões florais. Os substratos para violeta africana devem ser porosos, ricos em matéria orgânica, com boa drenagem. Iuchi (1994), trabalhando com rainha do abismo (Sinnigia leuctricha), obteve melhor desenvolvimento das plantas com o uso de areia mais húmus nas proporções de 2:1 ou 1:2.. Entretanto, melhores resultados foram obtidos por Hoffmann (1999), na aclimatização do porta-enxerto de macieira Marubakaido com o uso do substrato comercial plantmax ${ }^{\circledR}$.

Esses resultados evidenciam a necessidade de se ter proporções adequadas de componentes no substrato, principalmente de matéria orgânica, para o adequado desenvolvimento das plantas, visto que o substrato exerce influência significativa na arquitetura do sistema radicular, no estado nutricional das plantas e no movimento de água no sistema solo-planta- atmosfera.

Apesar de mudas de abacaxizeiro micropropagadas serem de fácil enraizamento é importante observar o desenvolvimento das raízes na fase de aclimatização visto que as raízes formadas ‘in vitro' não são funcionais quando transplantadas e por isso novas raízes devem ser formadas.

Vários substratos utilizados nesse experimento mostraram valores estatisticamente iguais para as variáveis analisadas relativas à raiz. No entanto, nota-se que os substratos 2, 4, 6 e 8 tiveram melhores resultados para as características avaliadas no sistema radicular, tendo estatisticamente comportamento semelhantes. A escolha de um ou outro, segundo Souza (1983), pode ser feita em função da disponibilidade.

TABELA 1 - Proporção dos materiais utilizados na constituição do substrato para aclimatização de mudas micropropagadas de abacaxizeiro cv. Pérola.

\begin{tabular}{ccccc}
\hline \multirow{2}{*}{ Tratamento } & \multicolumn{5}{c}{ Materiais (\%) } \\
\cline { 2 - 5 } & Solo & Esterco Bovino & Plantmax & Composto Orgânico \\
\hline 1 & 100 & - & - & - \\
2 & - & 100 & - & - \\
3 & - & - & 100 & - \\
4 & - & - & - & 100 \\
5 & 50 & 50 & - & - \\
6 & 50 & - & 50 & - \\
7 & 50 & - & - & 50 \\
8 & 40 & 30 & 30 & - \\
9 & 40 & 30 & - & 30 \\
10 & 40 & - & 30 & 25 \\
11 & 25 & 25 & 25 & \\
\hline
\end{tabular}


TABELA 2 - Valores médios de altura da planta (AP), comprimento de raiz (CR), número de folhas (NF), matéria seca (MSR) e fresca (MFR) de raiz (R), matéria fresca (MFA) e seca (MSA) da parte aérea de mudas obtidas 'in vitro' de abacaxizeiro cv. Pérola, em função de diferentes substratos durante a aclimatização.

\begin{tabular}{cccccccc}
\hline \multirow{2}{*}{ Substratos } & \multicolumn{7}{c}{ Variáveis } \\
\cline { 2 - 7 } & $\mathbf{A P}(\mathbf{c m})$ & $\mathbf{C R}(\mathbf{c m})$ & $\mathbf{N F}(\mathbf{u})$ & MFA $(\mathbf{g})$ & MFR $(\mathbf{g})$ & MSA $(\mathbf{m g})$ & MSR $(\mathbf{m g})$ \\
\hline 1 & $8,26 \mathrm{~d}$ & $8,90 \mathrm{~b}$ & $10,16 \mathrm{~d}$ & $3,33 \mathrm{~d}$ & $0,60 \mathrm{c}$ & $385,68 \mathrm{~b}$ & $107,88 \mathrm{~b}$ \\
2 & $11,32 \mathrm{c}$ & $11,17 \mathrm{a}$ & $14,62 \mathrm{c}$ & $7,55 \mathrm{c}$ & $0,84 \mathrm{c}$ & $782,38 \mathrm{a}$ & $123,91 \mathrm{a}$ \\
3 & $9,00 \mathrm{~d}$ & $12,12 \mathrm{a}$ & $13,08 \mathrm{c}$ & $5,63 \mathrm{~d}$ & $2,17 \mathrm{a}$ & $510,92 \mathrm{~b}$ & $191,57 \mathrm{a}$ \\
4 & $15,63 \mathrm{a}$ & $12,46 \mathrm{a}$ & $17,16 \mathrm{a}$ & $13,78 \mathrm{a}$ & $1,85 \mathrm{a}$ & $1148,61 \mathrm{a}$ & $231,30 \mathrm{a}$ \\
5 & $14,42 \mathrm{a}$ & $13,12 \mathrm{a}$ & $16,99 \mathrm{a}$ & $9,20 \mathrm{~b}$ & $1,54 \mathrm{~b}$ & $973,34 \mathrm{a}$ & $233,37 \mathrm{a}$ \\
6 & $11,95 \mathrm{c}$ & $13,91 \mathrm{a}$ & $15,49 \mathrm{~b}$ & $4,57 \mathrm{~d}$ & $1,82 \mathrm{a}$ & $505,80 \mathrm{~b}$ & $205,59 \mathrm{a}$ \\
7 & $13,30 \mathrm{~b}$ & $12,67 \mathrm{a}$ & $16,33 \mathrm{~b}$ & $7,90 \mathrm{c}$ & $1,14 \mathrm{~b}$ & $931,22 \mathrm{a}$ & $172,66 \mathrm{~b}$ \\
8 & $15,22 \mathrm{a}$ & $13,09 \mathrm{a}$ & $17,99 \mathrm{a}$ & $10,83 \mathrm{~b}$ & $2,49 \mathrm{a}$ & $1112,12 \mathrm{a}$ & $268,48 \mathrm{a}$ \\
9 & $13,22 \mathrm{~b}$ & $11,69 \mathrm{a}$ & $13,49 \mathrm{c}$ & $9,57 \mathrm{~b}$ & $1,33 \mathrm{~b}$ & $1041,24 \mathrm{a}$ & $248,45 \mathrm{a}$ \\
10 & $11,46 \mathrm{c}$ & $12,27 \mathrm{a}$ & $13,45 \mathrm{c}$ & $8,14 \mathrm{c}$ & $1,40 \mathrm{~b}$ & $771,59 \mathrm{a}$ & $207,82 \mathrm{a}$ \\
11 & $13,01 \mathrm{~b}$ & $11,62 \mathrm{a}$ & $13,50 \mathrm{c}$ & $10,01 \mathrm{~b}$ & $0,94 \mathrm{c}$ & $889,43 \mathrm{a}$ & $128,56 \mathrm{~b}$ \\
\hline
\end{tabular}

Médias seguidas por letras distintas, na vertical, diferem entre si ao nível de 5\% de probabilidade. 1) solo; 2) esterco; 3) plantmax; 4) composto orgânico; 5) solo + esterco; 6) solo + plantmax; 7) solo + composto orgânico; 8) solo + esterco + plantmax; 9) solo + esterco + composto orgânico; 10) solo + plantmax + composto orgânico; 11) solo + esterco + plantmax + composto orgânico.

\section{CONCLUSÃO}

A presença de matéria orgânica favorece o crescimento da parte aérea e raiz de plantas de abacaxizeiro cv. Pérola.

\section{REFERÊNCIAS BIBLIOGRÁFICAS}

BIASI, L. A. Avaliação do desenvolvimento inicial de portaenxerto e de mudas de videira obtidos através de diferentes métodos de propagação. 1996. 177 f. Tese (Doutorado em Agronomia) - Escola Superior de Agricultura de Luiz de Queiroz, Piracicaba, 1996.

CORSATO, C. E. Comportamento fisiológico do morangueiro (Fragaria $x$ ananassa Duch.) micropropagado e aclimatado na presença de fungos endomicorrízicos. 1993. 48 f. Dissertação (Mestrado em Fisiologia e Bioquímica de Plantas) - Escola Superior de Agricultura de Luiz de Queiroz, Piracicaba, 1993.

FAUTH, A.; TOFOL, M.; SILVA, A. L.; MARASCHIN, M. Aclimatação de mudas de abacaxi (Ananas comosus (L.)
Merril) resistentes à fusariose, cultivados 'in vitro'. Revista Brasileira de Fruticultura, Cruz das Almas, v. 16, n. 2, p. 7-12, set. 1994.

GRATTAPAGLIA, D.; MACHADO, M. A. Micropropagação. In: TORRES, A. C.; CALDAS, L. S. (Eds.). Técnicas e aplicações da cultura de tecidos de plantas. Brasília, DF: ABCTP/EMBRAPA, 1990. p. 99-169.

HOFFMANN, A. Enraizamento e aclimatização de mudas micropropagadas dos porta-enxertos de macieira 'Marubakaido e 'M-26'. 1999. 240 p. Tese (Doutorado em Fitotecnia) - Universidade Federal de Lavras, Lavras, 1999.

HOFFMANN, A.; CHALFUN, N. N. J.; ANTUNES, L. E. C.; RAMOS, J. D.; PASQUAL, M.; SILVA, C. R. de R. e. Fruticultura comercial: propagação de plantas frutíferas. Lavras: UFLA/FAEPE, 1996. 319 p.

IUCHI, V. L. Morfologia, biologia floral, propagação e crescimento de 'Rainha do Abismo' (Sinningia leucotricha (Hoehne) Moore). 1994. 168 f. Tese (Doutorado em Fitotecnia) - Universidade Federal de Viçosa, Viçosa, 1994. 
KIEHL, E. J. Fertilizantes orgânicos. Piracicaba: Agronômica Ceres, 1985. 492 p.

MOORE, G. A.; DeWALD, M. G.; EVANS, M. H. Micropropagation of pineapple (Ananas comosus L.). In: BAJAJ, Y. P. S. (Ed.). Biotecnology in agriculture and forestry 18: high-tech and micropropagation II. New York: Springer-Verlag, 1992. p. 461-470.

MULLER, C. H.; REIS, G. G. dos; MULLER, A. A. Influência do esterco no crescimento e no acúmulo de nutrientes em mudas de mamão Havaí (Carica papaya). Belém: CPATU, 1979. 14 p. (Comunicado técnico, 30).

NORMAH, M. N.; NOR-AZZA, A. B.; ALLIUDIN, R. Factors affecting in vitro shoot proliferation and ex vitro establishment of mangosteen. Plant Cell, Tissue and Organ Culture, Dordrecht, v. 43, n. 3, p. 291-294, Dec. 1995.

PASQUAL, M.; LOPES, P. A. Efeitos da concentração e tempo de incubação em ácido indolbutírico sobre o enraizamento e posterior desenvolvimento de brotos de Pyrus calleryana L. obtidos in vitro. Pesquisa Agropecuária Brasileira, Brasília, v. 26, n. 7, p. 975-980, 1991.

PAUL, J. L.; LEE, C. I. Relation between growth of Chrysantemum and aeration of conterainer media. Journal of the American Society for Horticultural Science, Alexandria, v. 101, p. 500-503, 1976.

PEIXOTO, J. R. Efeito da matéria orgânica, do superfosfato simples e do cloreto de potássio na formação de mudas do maracujazeiro amarelo (Passiflora edulis f. Favicarpa Deneger). 1986. 101 f. Dissertação (Mestrado em Fitotecnia) - Universidade Federal de Lavras, Lavras, 1986.

POOLE, R. T.; WATERS, W. E. Evaluation of various pottings media for growth of foliage plants. Proceedings of the Florida State Horticultural Society, Tallahasse, v. 85, p. 395-398, 1972.
RAIJ, B. van. Fertilidade do solo e adubação. Piracicaba: Ceres/Potafos, 1991. 343 p.

READ, P. E.; FELLMAN, C. D. Accelerating acclimation of in vitro propagated woody ornamentals. Acta Horticulturae, Wageningen, n. 166, p. 15-20, 1985.

SALVADOR, E. D. Caracterização física e formulação de substratos para o cultivo de algumas plantas ornamentais. 2000. 148 f. Tese (Doutorado em Produção Vegetal) - Escola Superior de Agricultura de Luiz de Queiroz, Piracicaba, 2000.

SILVA, A. B. Multiplicação in vitro e aclimatização de gloxínia (Sinningia speciosa Lodd. Hiern.). 2001. 59 p. Dissertação (Mestrado em Fitotecnia) - Universidade Federal de Lavras, Lavras, 2001.

SILVA, A. B. et al. Aclimatação de brotações de abacaxi (Ananas comusis L.) produzidas in vitro: ação de Agromix, húmus e Kelpak. Revista da Universidade de Alfenas, Alfenas, v. 4, n. 2, p. 107-110, 1998.

SOUSA, H. U. de. Efeito da composição e doses de superfosfato simples no crescimento e nutrição de mudas de bananeira (Musa sp) cv. Mysore obtidas por cultura de meristemas. 1994. 75 f. Dissertação (Mestrado em Fitotecnia) - Universidade Federal de Lavras, Lavras, 1994.

SOUZA, M. de. Nutrição e adubação para produzir mudas de frutíferas. Informe Agropecuário, Belo Horizonte, v. 9, n. 102, p. 40-43, jun. 1983.

SUTTER, E. G.; HUTZELL, M. Use of humidity tents and antitranspirants in the acclimatization to tissue-cultured plants to the greenhouse. Scientia Horticulturae, Amsterdam, v. 23, n. 4, p. 303-312, 1984.

ZIMMERMAN, R. H. Micropropagation of woody plants: post tissue culture aspects. Acta Horticulturae, Wageningen, n. 227, p. 489-499, 1988. 